\title{
Partisipasi Masyarakat Terhadap Tanaman Pala (Myristica fragrans) Di Kampung Kamandur Tetar Distrik Wartutin Kabupaten Fakfak
}

\author{
Lanny Wattimena $^{1}$; Yetti Serkadifat ${ }^{1}$; Terry Kabes $^{1}$ \\ 1) Dosen Universitas Victory Sorong \\ lannywattimena@gmail.com
}

\begin{abstract}
ABSTRAK
Hutan merupakan sumber kekayaan alam dan sumber penyangga bagi kehidupan. Hutan dapat menghasilkan hasil hutan kayu dan hasil hutan non kayu. Pala merupakan salah satu hasil hutan hasil hutan non kayu yang memiliki nilai ekonomis tinggi. Oleh sebab itu dibutuhkan partisipasi dari berbagai kalangan baik masyarakat kampung maupun pemerintah melalui dinas terkait. Penelitian ini bertujuan untuk mengetahui bentukbentuk partisipasi masyarakat terhadap tanaman pala (Myristica fragrans) di Kampung Kamandur Tetar Distrik Wartutin Kabupaten Fak-fak, serta mengetahui faktor-faktor yang mempengaruhi partisipasi masyarakat terhadap tanaman pala. Kampung Kamandur Tetar Distrik Wartutin Kabupaten Fak-fak merupakan lokasi penelitian, yang dilaksanakan pada bulan Agustus 2020. Objek yang diteliti tentang partisipasi masyarakat terhadap tanaman pala (Myristica fragrans). Metode wawancara dan observasi digunakan untuk pengumpulan data. Data yang diperoleh, dianalisis secara deskriptif, dan ditampilkan melalui tabel dan gambar. Hasil penelitian menunjukan bahwa Masyarakat Kampung Kamandur Tetar berpartisipasi aktif dalam setiap kegiatan yang berkaitan dengan pelestarian dan pengolahan tanaman pala. Partisipasi dilaksanakan dalam bentuk perencanaan, pelaksanaan, dan pengendalian kegiatan, serta pemanfaatan hasil. Faktor-faktor yang mempengaruhi partisipasi masyarakat terhadap tanaman pala adalah jenis kelamin, tingkat umur, tingkat pendidikan, jenis pekerjaan, dan lama tinggal.
\end{abstract}

Kata Kunci : Partisipasi Masyarakat, Tanaman Pala (Myristica fragrans), Kampung Kamandur Tetar.

\section{PENDAHULUAN}

Tanaman pala (Myristica fragrans) di Indonesia dikenal sebagai tanaman rempah rempah dan sangat penting karena memiliki banyak manfaat seperti minyak atsiri, bahan makanan, obat-obatan kosmetik dan lain-lain dan juga diperdagangkan di dalam negeri dan diluar negeri. Tanaman pala (Myristica fragrans) adalah tanaman asli Indonesia yang sangat potensial sebagai komoditas perdagangan di dalam dan di luar negeri (ekspor) berasal dari Pulau Banda. Tanaman pala dikategorikan sebagai tanaman umur panjang yang dapat hidup sampai 100 tahun lebih. Negara Indonesia telah menduduki posisi pertama penghasil pala dunia, karena sebagian besar kebutuhan pala dunia berasal dari Indonesia (Ratnawati Devi (2007) dalam Muhammad Rijal (2017).

Sumberdaya yang ada di Indonesia, baik sumber daya manusia maupun sumber daya alam tidak dapat menjadi patokan untuk pencapaian kemakmuran masyarakat di 
situasi negara yang cukup memprihatinkan. Harus ada perubahan dalam memperbaiki kondisi bangsa Indonesia yang sekarang ini. Oleh karena itu, masyarakat harus sadar untuk berperan aktif dalam melestarikan lingkungan hidup, tanggap terhadap informasi dalam penyelesaian masalah, dan dapat membuat keputusan untuk kepentingan bersama. Masyarakat yang sehat fisik dan mental, terdidik dan kuat, akan memiliki keberdayaan yang tinggi. Sehingga pemberdayaan perlu dilakukan dalam usaha pengelolaan lingkungan Kartasasmita (1996).

Inti dari pembangunan yang partisipatoris adalah kemandirian. Dalam arti, diperlukannya suatu interaksi dan saling ketergantungan semua pihak yang terlibat dalam pembangunan (baik pemerintah, maupun lembaga-lembaga dari luar) untuk memobilisasi energi dan sumber daya yang tersedia di dalam masyarakat sebagai faktor kunci bagi tumbuhnya kegiatan-kegiatan untuk meningkatkan produktivitas dan kemandirian mereka. Oleh sebab itu diperlukan partisipasi masyarakat. Partisipasi hendaknya dipandang sebagai hasil dari pembangunan (Saragih, 1992 dalam Afifah Tri Murwidiyani. 2008).

Daerah penghasil pala terbanyak di Provinsi Papua Barat adalah di Kabupaten Fakfak yang hampir 80 persen lahan ditanami tanaman pala, dan tersebar di delapan distrik, termasuk Distrik Watrutin. Pala Fakfak banyak tumbuh di hutan. Petani juga membudidayakan benih menggunakan benih turunan pohon pala dari hutan tersebut. Pertanaman pala berupa pertanaman homogen. Umur tanaman mencapai 30 - 100 tahun. Pala Fakfak memiliki karakteristik bentuk tanaman yang tinggi dan berdaun rimbun, berbeda dengan pala Banda. Pengembangan Pala Fakfak oleh Pemerintah ditandai dengan dikeluarkan varietas unggul Pala Fakfak pada tahun 2017 dengan Keputusan Menteri Pertanian Republik Indonesia nomor 95/Kpts/KB.010/2/2017. Terdapat 126 Pohon Induk Terpilih (PIT) sebagai sumber benih yang merupakan hasil seleksi. Pada tahun 2017 luas areal tanaman pala di Kabupaten Fakfak mencapai 17.542 hektar dengan produksi mencapai 1.750 ton (BPS Fakfak, 2018).

Tanaman pala memberikan manfaat bagi masyarakat Kampung Kamandur Tetar yang memanfaatkan tanaman pala untuk menghasilkan pendapatan, sehingga pemanfaatan yang berkelanjutan sangat diperlukan. Oleh sebab itu, perlu diketahui bagaimana partisipasi masyarakat terhadap tanaman pala khususnya masyarakat yang tinggal sekitar kawasan hutan.

Tujuan dari penelitian ini adalah untuk mengetahui bentuk-bentuk partisipasi, serta mengetahui faktor-faktor yang mempengaruhi partisipasi masyarakat terhadap tanaman pala (Myristica fragrans) di Kampung Kamandur Tetar Distrik Wartutin Kabupaten Fakfak. Hasil penelitian ini diharapkan dapat bermanfaat bagi masyarakat Fakfak pada umumnya dan terlebih khusus bagi masyarakat Kampung Kamandur Tetar dalam melestarikan dan mengolah tanaman pala; sebagai informasi untuk Pemerintah Kabupaten Fakfak khususnya Dinas terkait agar dapat memberikan bantuan berupa dana dan bibit tanaman pala serta harga yang memuaskan bagi masyarakat; dan sebagai bahan informasi bagi penelitian selanjutnya. 


\section{METODE PENELITIAN}

Kampung Kamandur Tetar Distrik Wartutin Kabupaten Fakfak Provinsi Papua Barat merupakan lokasi penelitian, yang dilaksanakan pada bulan Agustus 2020. Objek yang diteliti adalah masyarakat Kampung Kamandur Tetar yang masih memanfaatkan tanaman pala. Alat yang digunakan adalah kuisioner, kamera, dan alat tulis.

Data diperoleh melalui (1) Metode Interview (menggunakan kuisioner dengan teknik wawancara). Metode Interview atau metode wawancara digunakan untuk mencari data dari objek penelitian; (2) Metode Dokumentasi, berupa dokumendokumen, sarana prasarana, dan struktur organisasi kampung.

Variabel penelitian meliputi bentuk partisipasi masyarakat terhadap tanaman pala dan faktor-faktor yang mempengaruhi partisipasi masyarakat. Teknik penentuan sampel adalah secara purposive sampling, yang mana pengambilan sampel berdasarkan pada suatu pertimbangan tertentu seperti sifat, populasi, serta karakteristik yang ditentukan berdasarkan informasi sebelumnya (Notoatmodjo, 2010). Suharsimi Arikunto, dkk (2008) menyatakan bahwa penentuan penarikan sampel adalah apabila subjek/objek yang diteliti kurang dari 100 lebih baik diambil semuanya. Jika jumlah subjek/objeknya besar dapat diambil antara $10-15 \%$ atau $20-55 \%$ atau lebih tergantung sedikit banyaknya kemampuan peneliti dilihat dari waktu, tenaga dan dana. Dalam penelitian ini respondennya adalah masyarakat Kampung Kamandur Tetar, yang masih memanfaatkan tanaman pala yang berjumlah 50 orang responden yang masih memanfaatkan tanaman pala.

Zuldafrial (2012) mengatakan bahwa sumber data adalah dimana data dapat diperoleh. Ada 2 (dua) jenis sumber data yaitu sumber data primer dan sumber data sekunder. Data primer dalam penelitian ini diperoleh langsung dari hasil wawancara peneliti dengan 50 orang responden masyarakat Kampung Kamandur Tetar. Sedangkan data sekunder diperoleh dari pihak pemerintah kampung dan pihak lain yang berkaitan langsung dengan penelitian ini. Data penelitian akan dianalisis secara deskriptif dan dibuat dalam bentuk tabel dan angka.

\section{HASIL DAN PEMBAHASAN}

\section{Bentuk-Bentuk Partisipasi}

Partisipasi merupakan suatu proses yang menggerakkan peran serta masyarakat dalam kegiatan-kegiatan pembangunan. Partisipasi dapat secara langsung maupun perwakilan. Untuk menumbuhkan partisipasi, diperlukan adanya kemauan, kemampuan dan kesempatan yang diberikan kepada masyarakat (Bappenas, 2007 dalam Afifah Tri Murwidiyani, 2008).

Partisipasi yang dilakukan oleh masyarakat Kampung Kamandur Tetar adalah secara langsung, artinya masyarakat berpatisipasi langsung dalam kegiatan-kegiatan yang berkaitan dengan pemanfaatan tanaman pala. Setiap Kepala Keluarga memiliki dusun atau lahan tanaman pala (Myristica fragrans) milik pribadi. 
Adapun bentuk-bentuk partisipasi yang diikuti, meliputi :

\section{Partisipasi dalam Bentuk Perencanaan Kegiatan}

Partisipasi dalam perencanaan, merupakan partisipasi masyarakat dalam mengambil keputusan secara langsung tentang program pembangunan di Kabupaten Fak-fak khususnya di Kampung Kamandur Tetar.

Keterlibatan masyarakat di Kampung Kamandur Tetar adalah dalam bentuk kehadiran mengikuti sosialisasi yang berkaitan dengan kegiatan dari Dinas Pertanian mengenai pengembangan tanaman pala tersebut.

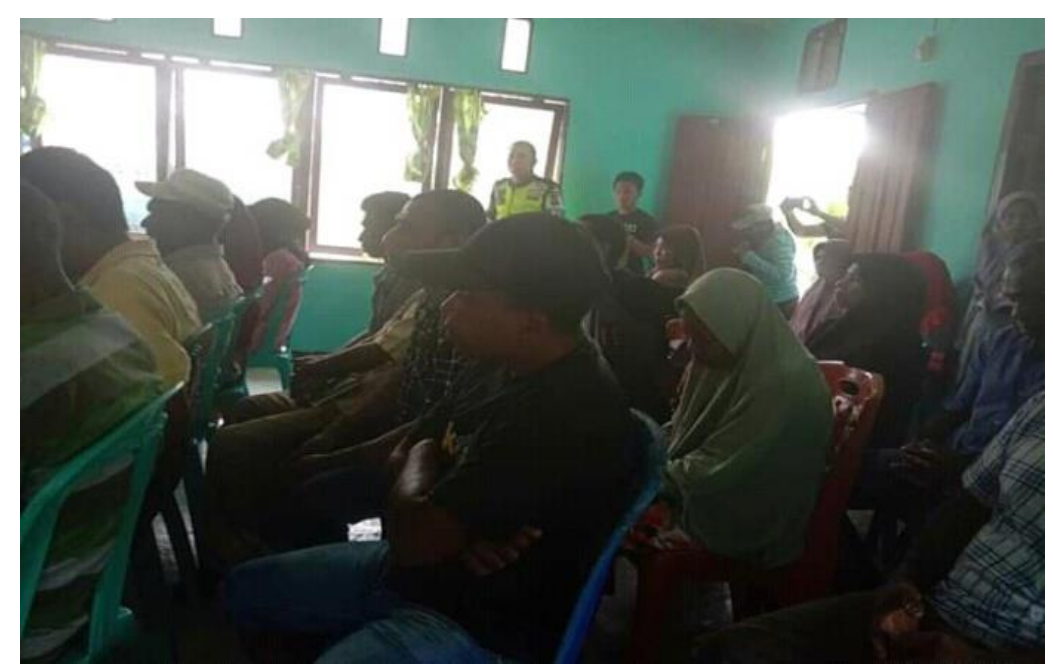

Gambar 1. Bentuk Keterlibatan Masyarakat Dalam Mengikuti Sosialisasi Pelestarian Tanaman Pala Di Kampung Kamandur Tetar.

Keterlibatan masyarakat dalam mengikuti sosialisasi pelestarian tanaman pala dari dinas terkait, diharapkan memberikan manfaat, yaitu tambahan ilmu pengetahuan dan informasi. Masyarakat diharapkan dapat memahami langkah-langkah pelestarian dan pengelolaan tanaman pala dengan baik dan benar, serta dapat mengimplentasikannya ketika berusahani.

\section{Partisipasi Dalam Bentuk Pelaksanaan Kegiatan}

Partisipasi dalam pelaksanaan kegiatan, merupakan pemerataan sumbangan masyarakat dalam bentuk kemampuan jasmani dan materi yang diberikan, sehingga hasil dan manfaat yang diperoleh dapat dirasakan oleh masyarakat.

Keterlibatan masyarakat kampung kamandur tetar dalam pelaksanaan kegiatan meliputi keikutsertaan masyarakat dalam penanaman bibit tanaman pala pada lahan yang telah disediakan serta ikut mengolah hasil panen yang telah dikeringkan, dan diambil bijinya untuk dijual.

Penanaman bibit pala dilakukan masyarakat untuk membudidayakan tanaman tersebut, sehingga dapat memberikan hasil yang lebih baik di masa depan dan dapat dinikmati oleh generasi berikutnya.

Pengolahan hasil panen tanaman pala dianggap penting karena dapat memberikan nilai tambah pada hasil pertanian dan menambah pendapatan masyarakat. Masyarakat 


\section{Median Volume 12 Nomor 3 Bulan Oktober 2020}

Doi http://doi.org/md.v12i3.441

dianjurkan untuk mengolah sendiri hasil panen tanaman pala sehingga memperoleh mutu terbaik dan harga yang lebih tinggi, demi kemakmuran masyarakat.

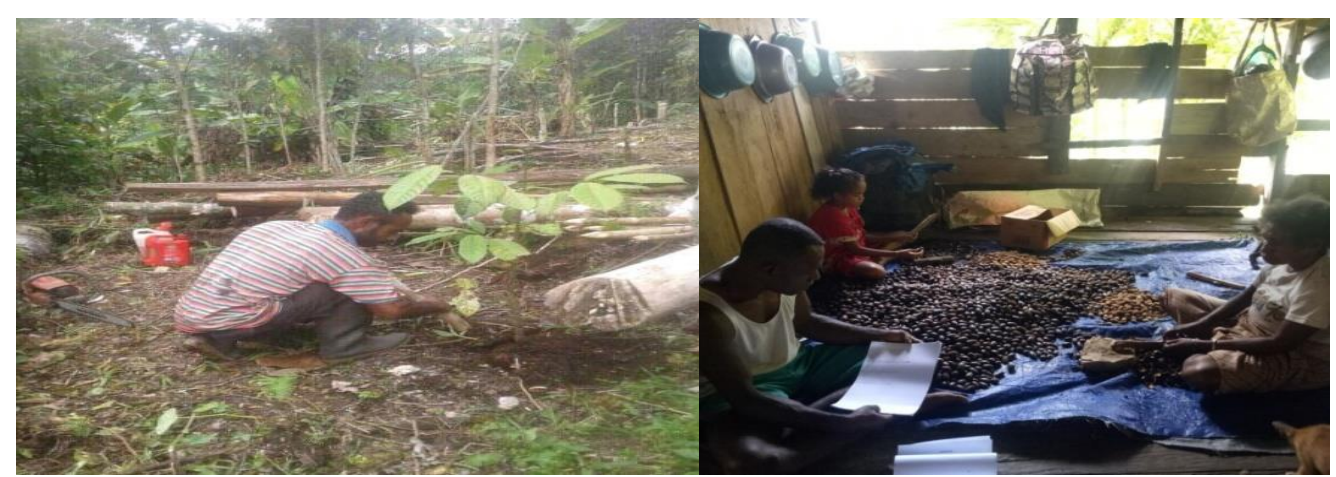

Gambar 2. Partisipasi masyarakat dalam penanaman dan pengolahan hasil panen.

Buah pala dipetik langsung dari pohon, dan juga buah yang berjatuhan dapat dipungut. Buah pala yang sudah tua, fulinya berwarna merah. Tempurung bijinya mengkilat dan berwarna coklat tua. Kemudian fuli dihemparkan pada alas yang bersih lalu dijemur setelah dilepas dari bijinya. Penjemuran fuli membutuhkan waktu 2-3 hari kalau cuaca cerah. Setelah kering fuli disimpan. Sedangkan biji pala yang belum kering, dijemur atau diangin-anginkan selama kurang lebih 6 minggu, sehingga menghasilkan biji pala yang bagus (tidak keriput).

\section{Partisipasi dalam Pengendalian Kegiatan}

Keterlibatan masyarakat dalam pengendalian atau pengawasan kegiatan dalam pengadaan bibit pala untuk ditanam yaitu diambil bibitnya dari kota dan di bawah ke kampung menggunakan kendaraan roda 4 (truck pickup).

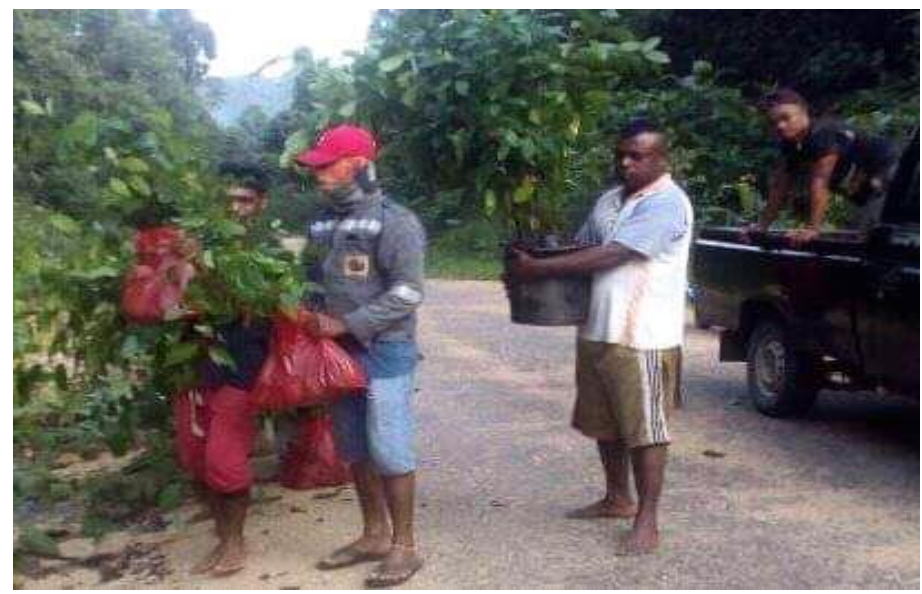

Gambar 3. Keterlibatan masyarakat dalam pengawasan pengadaan bibit.

\section{Partisipasi dalam Pemanfaatan Hasil}

Partisipasi dalam pemanfataan hasil adalah sejauh mana masyarakat Kamandur Tetar merasakan manfaat dari adanya kegiatan pengembangan tanaman pala. Keterlibatan masyarakat dalam memanfaaatkan hasil dari tanaman pala yaitu menjual 


\section{Median Volume 12 Nomor 3 Bulan Oktober 2020}

Doi http://doi.org/md.v12i3.441

hasil panen pada pedagang atau pembeli yang berada di Kota Fakfak. Masyarakat menggunakan kendaraan laut atau darat untuk menuju ke kota. Penjualan hasil panen bertujuan untuk membeli keperluan rumah tangga.

Bagian yang diambil dari buah pala untuk diolah adalah (1) Daging buah pala; (2) Fuli atau bunga pala; (3) Bagian biji yang berwarna kecoklatan, pada bagian ini paling banyak dimanfaatkan (Muhammad Rijal, 2017). Hasil panen dari tanaman pala oleh masyarakat Kamandur Tetar meliputi:

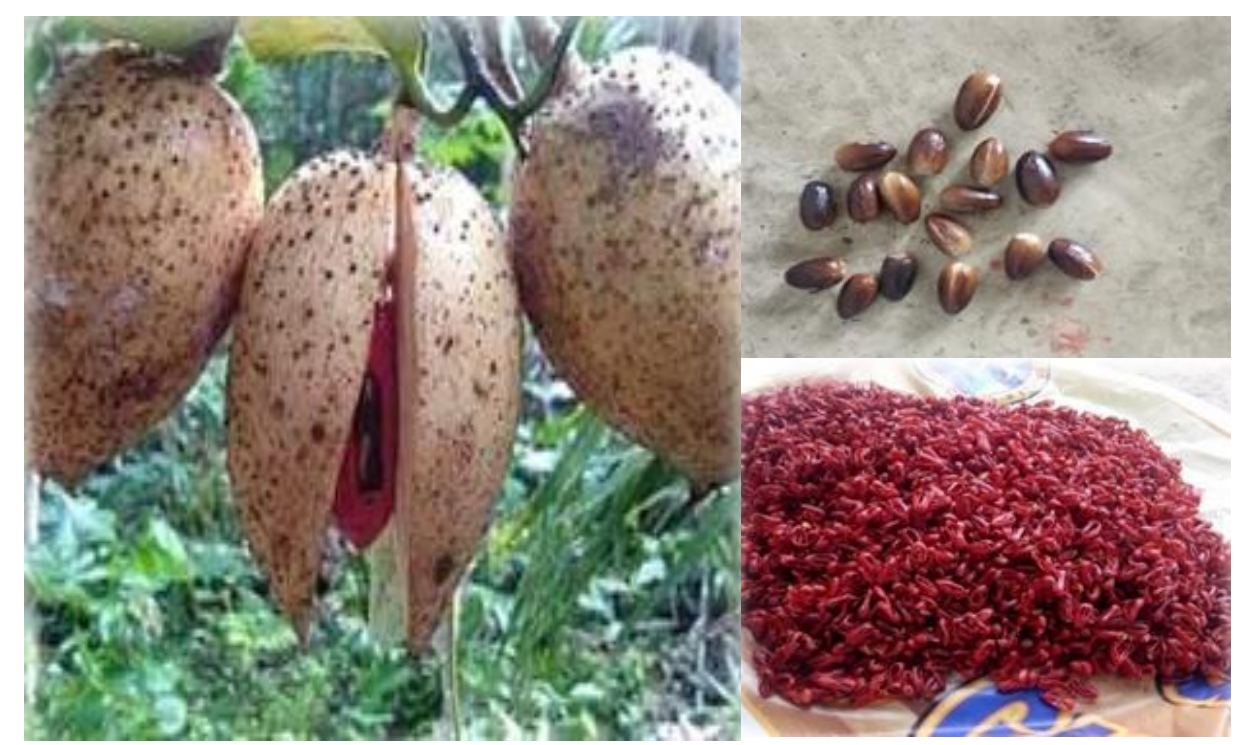

Gambar 4. Bakal Buah, Biji (dalam tempurung), Bunga Pala (Fuli).

Pala yang dipanen oleh masyarakat digunakan untuk bumbu dapur (rempahrempah). Selain itu juga bagian-bagian dari tanaman pala yang dimanfaatkan yaitu:

1. Fuli atau buah pala yang disebut bunga pala, dikeringkan dan dijual.

2. Biji pala digunakan untuk bumbu dapur (rempah-rempah) dan obat-obatan tradisional.

3. Daging buah pala dimanfaatkan untuk membuat asinan atau manisan pala, dan selai pala.

4. Batang atau kayu pohon pala dimanfaatkan sebagai kayu bakar.

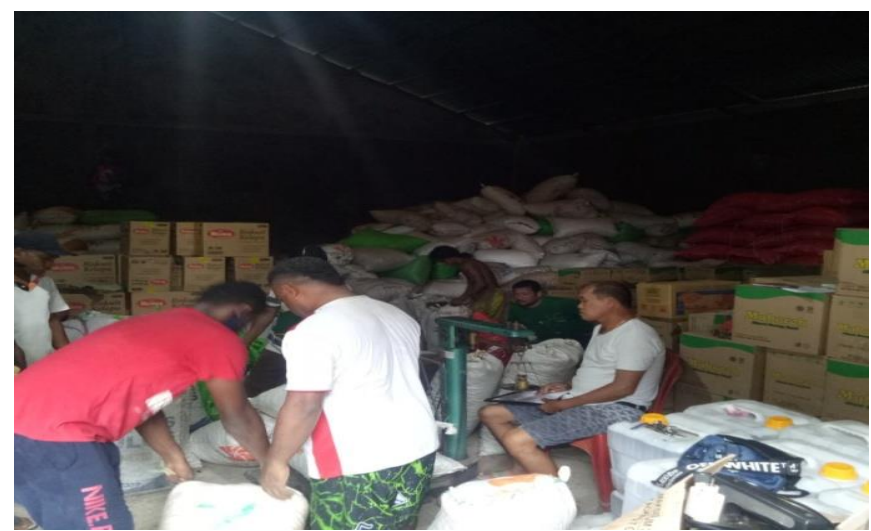

Gambar 5. Partisipasi masyarakat dalam menjual hasil panen. 


\section{Faktor-faktor yang mempengaruhi Partisipasi}

Faktor-faktor yang mempengaruhi partisipasi masyarakat terhadap tanaman pala di Kampung Kamandur Tetar Distrik Wartutin Kabupaten Fakfak, meliputi :

\section{Jenis Kelamin}

Berdasarkan jenis kelamin maka yang dominan dalam berpartisipasi terhadap tanaman pala di Kampung Kamandur Tetar adalah laki-laki sebanyak 36 orang atau sebesar 72 persen dan yang paling sedikit adalah perempuan sebanyak 14 orang atau 28 persen, disebabkan karena laki-laki adalah tulang punggung keluarga yang berperan penting dalam pemenuhan kebutuhan keluarga.

Tabel 1. Karakteristik Responden menurut Jenis Kelamin

\begin{tabular}{cccc}
\hline No. & Jenis Kelamin & Jumlah (orang) & Persentase $(\%)$ \\
\hline 1 & Laki-laki & 36 & 72 \\
2 & Perempuan & 14 & 28 \\
\hline & Total & 50 & 100
\end{tabular}

Sumber : Data Olahan Penelitian, 2020

\section{Tingkat Umur}

Jika dilihat dari segi umur maka masyarakat Kampung Kamandur Tetar yang ikut berpartisipasi terhadap tanaman pala paling banyak berada pada kelompok umur 20-40 tahun sebanyak 28 orang responden atau sebesar 56 persen, karena mereka berada pada usia produktif. Dengan demikian membuktikan bahwa usia tidak menjadi kendala dalam berusahatani.

Tabel 2. Karakteristik Responden menurut Umur

\begin{tabular}{cccc}
\hline No. & Umur (tahun) & Jumlah (orang) & Persentase (\%) \\
\hline 1 & $20-40$ & 28 & 56 \\
2 & $41-60$ & 12 & 24 \\
3 & $\geq 61$ & 10 & 20 \\
\hline & Total & $\mathbf{5 0}$ & $\mathbf{1 0 0}$
\end{tabular}

Sumber : Data Olahan Penelitian, 2020

\section{Tingkat Pendidikan}

Berdasarkan tingkat pendidikan, sebanyak 24 orang responden atau 48 persen menyelesaikan pendidikan sampai ke jenjang Sekolah Dasar (SD). Dengan tingkat pendidikan yang rendah, tidak mempengaruhi masyarakat Kampung Kamandur Tetar dalam berusahatani pala, tetapi mereka membuka diri menerima ilmu pengetahuan dan informasi dari pemerintah melalui dinas terkait dalam mengelola tanaman tersebut.

Tabel 3. Karakteristik Responden menurut Tingkat Pendidikan

\begin{tabular}{clcc}
\hline No. & Tingkat Pendidikan & Jumlah (orang) & Persentase (\%) \\
\hline 1 & PAUD & - & - \\
2 & TK & - & - \\
3 & SD & 24 & 48 \\
4 & SMP & 15 & 30 \\
5 & SMA/SMK & 9 & 18 \\
\hline
\end{tabular}


Median Volume 12 Nomor 3 Bulan Oktober 2020

Doi http://doi.org/md.v12i3.441

\begin{tabular}{rrcc}
\hline 6 & SARJANA & 2 & 4 \\
\hline Total & $\mathbf{5 0}$ & $\mathbf{1 0 0}$
\end{tabular}

Sumber : Data Olahan Penelitian, 2020

\section{Jenis Pekerjaan}

Jenis pekerjaan pada masyarakat di Kampung Kamandur Tetar sebagian besar adalah petani. Selain itu masyarakat juga berprofesi sebagai nelayan dan pegawai negeri sipil.

Tabel 4. Karakteristik Responden Menurut Jenis Pekerjaan

\begin{tabular}{|c|l|c|c|}
\hline No. & Jenis Pekerjaan & Jumlah (orang) & Persentase (\%) \\
\hline 1 & Petani & 45 & 90 \\
\hline 2 & Nelayan & 3 & 6 \\
\hline 3 & Pegawai & 2 & 4 \\
\hline \multicolumn{2}{|c|}{ Total } & $\mathbf{5 0}$ & $\mathbf{1 0 0}$ \\
\hline
\end{tabular}

Sumber : Data Olahan Penelitian, 2020

Tabel 4 menunjukkan bahwa jenis pekerjaan yang paling banyak dilakukan adalah sebagai petani sebanyak 45 orang atau sebesar 90 persen. Pekerjaan sebagai petani pala adalah menjaga dan mengembangkan tanaman pala sebagai tanaman umur panjang dan merupakan peninggalan orang tua. Tanaman pala paling diperhatikan, dan yang paling banyak dibudidayakan di Kampung Kemandur Tetar, karena hasil panen tanaman ini dapat memberikan tambahan finansial.

\section{Lama Tinggal}

Lama tinggal juga sangat mempengaruhi partisispasi seseorang karena semakin lama seseorang tinggal atau menempati suatu tempat, maka tingkat partisipasinya tinggi terhadap kegiatan yang terjadi di tempat tersebut.

Tabel 5. Lama Tinggal

\begin{tabular}{cccc}
\hline No. & Lama Tinggal (tahun) & Jumlah (orang) & Persentase (\%) \\
\hline 1 & $20-25$ & 6 & 12 \\
2 & $26-30$ & 6 & 12 \\
3 & $31-35$ & 6 & 12 \\
4 & $36-50$ & 18 & 36 \\
5 & 51 tahun ke atas & 14 & 28 \\
\hline \multicolumn{2}{r}{ Total } & $\mathbf{5 0}$ & $\mathbf{1 0 0}$ \\
\hline
\end{tabular}

Sumber : Data Olahan Penelitian, 2020

Berdasarkan Tabel 5, maka responden paling lama tinggal atau mendiami lokasi penelitian adalah sekitar 36-50 tahun. Masyarakat Kampung Kamandur Tetar adalah masyarakat asli yang memang sudah dari lahir dan mendiami tempat tersebut. 


\section{PENUTUP}

1. Masyarakat Kampung Kamandur Tetar berpartisipasi aktif dalam setiap kegiatan yang berkaitan dengan tanaman pala, meliputi partisipasi dalam bentuk perencanaan, pelaksanaan, dan pengendalian kegiatan, serta pemanfaatan hasil.

2. Faktor-faktor yang mempengaruhi partisipasi masyarakat terhadap tanaman pala (Myristica fragrans) di Kampung Kamandur Tetar adalah jenis kelamin, tingkat umur, tingkat pendidikan, jenis pekerjaan, dan lama tinggal.

\section{DAFTAR PUSTAKA}

Afifah Tri Murwidiyani. 2008. Partisipasi Masyarakat Dalam Kegiatan Budidaya Tanaman Jarak Pagar (Jatropha curcas) Sebagai Bahan Bakar Alternatif Di Kabupaten Sukohardjo. [Skripsi] Surakarta : Fakultas Pertanian Universitas Sebelas Maret.

Arikunto, Suharsimi., dkk. 2008. Penelitian Tindakan Kelas. Jakarta : Bumi Aksara.

Badan Pusat Statistik. 2018. Kabupaten Fakfak Dalam Angka.

Hamijoyo. 2007. Pembangunan Masyarakat Berwawasan Partisipasi. Yogyakarta : UGM Press.

Holil, S. 2007. Partisipasi Sosial dalam Usaha Kesejahteraan Sosial. Bandung.

Imam Hanafie \& Hanawiyah Hanafie. 2010. Pengantar Ekonomi Pertanian. Yogyakarta : CV. Andi Offset.

Kartasasmita, G. 1996. Pembangunan untuk Rakyat : Memadukan Pertumbuhan dan Pemerataan. Jakarta : CIDES.

Muhammad Rijal. 2017. Pengolahan Daging Buah Pala dan Pengujiannya. Yogyakarta : Penerbit DEEPUBLISH.

Notoatmodjo, S. 2010. Metodologi Penelitian Kesehatan. Jakarta : Rineka Cipta.

Pamudji S. 1980. Kepemimpinan Pemerintahan di Indonesia. Bandung : Bumi Aksara.

Soekamto. 1990. Sosiologi Suatu Pengantar. Jakarta : Rajawali Pers.

Sugiyono. 2008. Metode Penelitian Kuantitatif Kualitatif dan R\&D. Bandung : ALFABETA.

Syifa Nuri Khairunnisa. 2020. Kompas.com dengan judul "Apa Itu Pala Fakfak? Rempah Kaya Manfaat untuk Dijadikan Sirup". https://www.kompas.com/food/read/2020/08/02/215500175/apa-itu-pala-fakfakrempah-kaya-manfaat-untuk-dijadikan-sirup?page $=$ all.

Dibagikan pada tanggal 02/08/2020, pukul 21:55 WIB.

Zuldafrial, Muhammad, Lahir. 2012. Penelitian Kualitatif. Surakarta : Yuma Pustaka. 